\title{
Staffing and Training Aspects of Hospital Management: Some Issues for Research
}

\author{
Julio Frenk, Enrique Ruelas, \\ and Avedis Donabedian
}

Throughout the world, hospitals have come to epitomize modern medical care. For many years, a major health policy concern was to provide communities with enough hospitals. More recently, the focus of concern has shifted to what is now considered the overly dominant role of the hospital within the health system. In developed nations there are outright diagnoses of an excess of beds, and the concern in most developing countries is that, even without having fully satisfied overall requirements for hospitals, these institutions already absorb such a high proportion of resources that they seriously threaten any effort to achieve full coverage of the population. Further, it is widely believed that a health care system centered on hospitals has intrinsic incompatibilities with the geographic, economic, and cultural attributes of many populations. In addition, the mix of services offered by hospitals-with their emphasis on acute, episodic, and curative activities-is believed not to match the

Julio Frenk, M.D., M.P.H., Ph.D. is Director-General, National Institute of Public Health of Mexico; Enrique Ruelas, M.D., M.P.A., M.Sc. is Dean, School of Public Health of Mexico, National Institute of Public Health; and Avedis Donabedian, M.D., M.P.H. is Nathan Sinai Distinguished Professor of Public Health, Department of Health Services Management and Policy, School of Public Health, The University of Michigan, Ann Arbor. 
prevailing epidemiologic profile and the population needs for preventive and continuous care. This inconsistency is becoming even more marked as an increasing number of countries undergo a profound epidemiologic transition (Omran 1971; Frederiksen 1969; Frenk, Bobadilla, Sepúlveda, et al. 1989) whereby chronic ailments are becoming more important, with the ensuing requirements for long-term services that most general hospitals traditionally have not been able to offer. As in the case of physician supply (Starr 1982), we seem with hospitals to have moved from deficit to excess without ever having achieved some kind of equilibrium.

It should be evident that a health system dominated by hospitals is not the only possible organizational model. Indeed, for most of the history of health care, hospitals represented a rather marginal element. As Foucault (1978) points out, during a long period of time the hospital was a nonmedical institution, and medicine was not a hospital-based profession. "The hospital as a therapeutic instrument is a relatively modern concept, dating from the end of the eighteenth century" (Foucault 1978, 20). Since then, a number of social, economic, cultural, scientific, and technologic changes-summarized by Rosen (1963), among others-have made the hospital the "fulcrum of care" (Berki 1972, 8).

The dominance of hospitals is one of the most striking characteristics of convergence among the health systems of countries at all levels of economic development and with all forms of political representation (Mechanic 1975; Frenk and Donabedian 1987). Together with the important progress that they have produced, hospitals have also given rise to the set of concerns mentioned earlier. As the ambitious goal of the World Health Organization-"Health for All by the Year 2000"-is universally adopted, it becomes crucial to understand the functioning of that segment of the worldwide health care system where most resources are expended. UNICEF has estimated that, while in many countries 85 percent of the national health budget is spent on them, hospitals take care of less than 10 percent of the population. To give one illustrative example: hospitals in Mexico represent fewer than 1 percent of all Ministry of Health facilities but concentrate over 40 percent of the physicians and nurses employed by the Ministry (Secretaria de Salud 1985).

Many countries face, therefore, a double concentration of health care: geographic concentration in large urban areas and technological concentration in large hospitals (Soberón, Frenk, and Sepúlveda 1986). The problem is further compounded by the effects of concentration on the organization of resources. For instance, efforts at regionalization have been bedeviled by the tendency of hospitals to encompass all three levels of care-primary, secondary, and tertiary. This is due in part to the 
weakness of primary health care, which makes it necessary for the outpatient departments of many hospitals to become major providers of firstcontact services. In this way, the concentration of resources in hospitals is both a cause and an effect of the weakness of primary health care. Another reason for the admixture of levels of care is the tendency toward transforming sections of many general hospitals into tertiary areas, that is to say, introducing highly specialized services into the context of organizations whose central mission is to provide basic hospital care. In either case, the result is a lack of clear patterns of patient referral, difficulties in assigning defined population bases to different types of health care facilities, the coexistence in the same facility of cases of widely varied complexity, and an inefficient use of resources.

Despite recent trends toward the "dehospitalization" of health care systems through the introduction of ambulatory alternatives in areas such as surgery, uncomplicated deliveries, and diagnosis, hospitals are likely to maintain their central position in the foreseeable future. Considerable thought and study need to be given to the overall design of health care systems and to the position of hospitals of different types in such a system. But irrespective of the design or designs that ultimately emerge, it is clear that hospitals will continue to play a major role; they will remain as fundamental forces in determining the overall performance of the health system. Any efforts to improve such performance must inevitably give the highest priority to hospital efficiency.

Such is the perspective that guides this article. Our purpose is to discuss some fundamental issues of hospital management, with special emphasis on staffing and training. To this end, the article is divided into three parts. First, we offer an analytical framework that can help orient the discussion. Hospitals are conceived of as complex organizations with goals, tasks, control systems, and relationships of authority that are articulated in both formal and informal ways (Scott 1966). We conceptualize the performance of the hospital in terms of three different types of efficiency: managerial, clinical, and production. We also analyze the elements of the internal organization design and of the external environment that influence the level of performance. In the second part of the article, we identify some issues that refer to each of the elements of the analytical framework. Finally, the third part presents a research agenda that may help create a better understanding of the issues, leading thereby to the design of more efficient health systems. Most of our discussion is intended to pertain to both developed and developing countries. In this respect, it may contribute to the elaboration of a broad comparative perspective on health care. 


\section{ANALYTICAL FRAMEWORK}

\section{THE ACTORS: CLINICIANS AND MANAGERS}

Figure 1, a schematic model for the study of hospital performance, begins (from the left) by positing that two groups of actors-managers and clinicians-assume the major roles. Needless to say, there are many different subgroups within each of the two major types. Among the managers, there are distinct levels, ranging from some members of the directorate to senior executives to the middle and lower echelons. Similarly, clinicians are heterogeneous, comprising a variety of professions. In this article we simplify the analysis somewhat by consolidating the managerial role, without distinctions by level, and by selecting physicians to represent the clinician role. It is appropriate to focus on physicians because they still constitute the principal group of providers, in terms of their number, importance, autonomy, and the economic consequences of their decisions.

Insofar as the same person can have both managerial and clinical functions, we speak of roles rather than occupational groups (Allison, Dowlig, and Munson 1983). This is particularly important with regard to physicians, who often occupy important administrative positions in hospitals. For the purposes of this article, when a physician assumes the managerial role, we view him or her as a manager. As we discuss later on, one of the issues in health care organizations is precisely the appropriateness of having physicians perform administrative functions. For the time being, however, the point is that the actors are conceived of in terms of their roles and not in terms of their professional origins.

As shown in Figure 1, the two basic groups of actors interact within the framework of a complex organization, the hospital. This interaction is affected by the specific design that the organization adopts. Further, the organization itself is surrounded by an environment, where it interacts with other organizations and with formal and informal groups of clients. Through its environment, the organization is shaped, as we see later on, by complex epidemiologic, economic, and sociopolitical processes.

\section{THREE TYPES OF EFFICIENCY}

Within the context of specific environments and organizational designs, the core of Figure 1 portrays a dynamic conception of the interaction between managers and clinicians. Through the operation of certain intervening variables, the interaction generates a set of products. The quantity and quality of these products is determined by the efficiency of the 


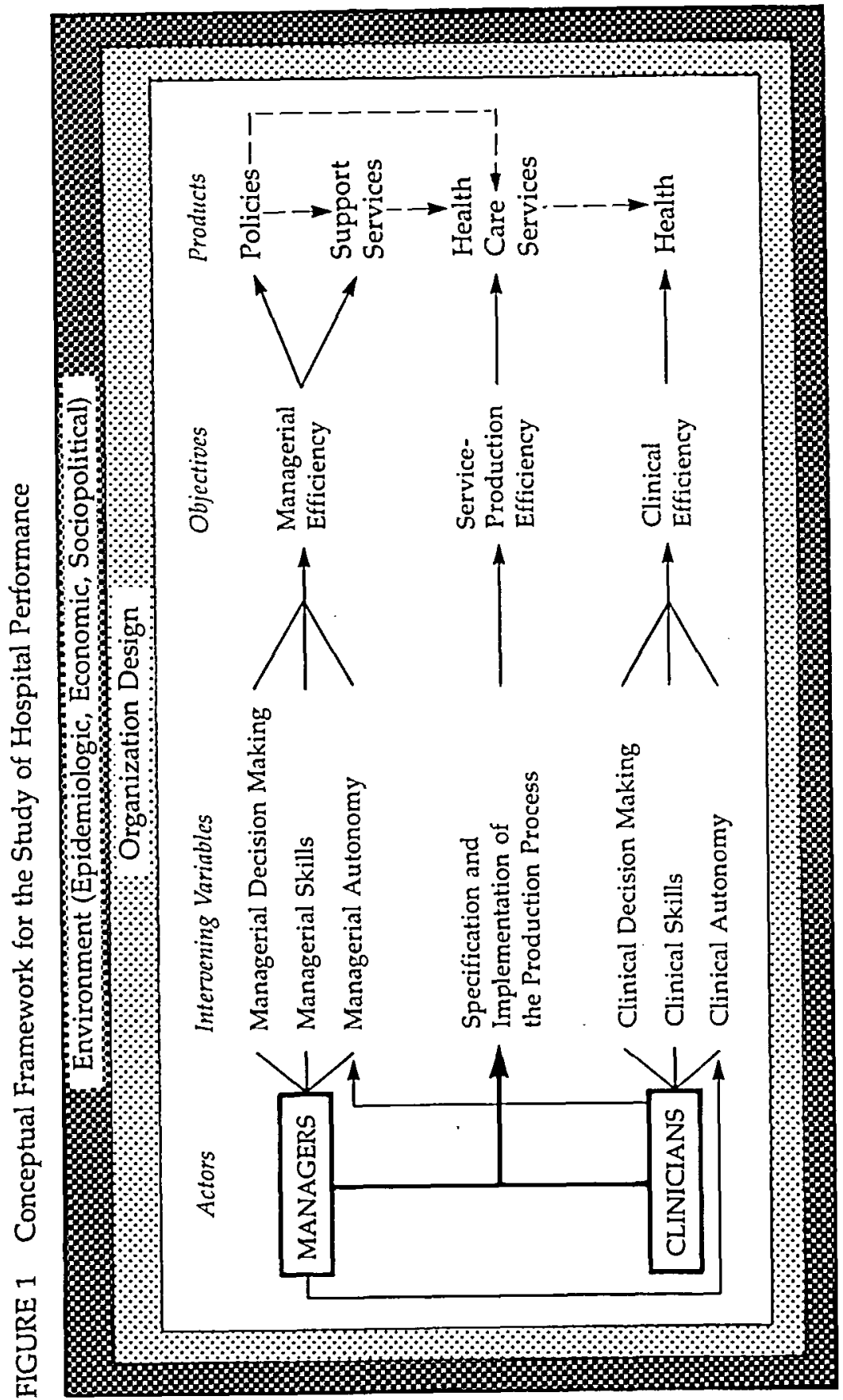


organization. In this regard, we propose that three types of efficiency are at work, and that they should be kept analytically distinct. We call these clinical efficiency, service-production efficiency, and managerial efficiency.

The distinction between clinical efficiency and production efficiency has been proposed by Donabedian, Wheeler, and Wyszewianski (1982). Basically, clinical efficiency refers to the production of health, however defined, whereas production efficiency has to do with the production of health services. Thus, clinical efficiency is the extent to which a physician "combines, times, and sequences services . . . to produce the greatest increment of health, given a specified available or permissible expenditure" (pp. 984-85). These authors refer to the combination, timing, and sequencing of health services in the management of a case as a "strategy of care." Hence, clinical efficiency is the efficiency of the strategies of care. The clinically most efficient strategy will be the one that produces the largest improvement of health for a given amount of expenditure or, alternatively, the one that produces a certain level of health with the least costly utilization of resources. Needless to say, the improvement in health status must be attributable to the strategy of care.

The question arises about how clinical efficiency is related to the quality of care. In elucidating this relationship, it is necessary to distinguish clinical efficiency from clinical effectiveness. The latter means the degree to which attainable health improvements are achieved, irrespective of the means utilized (quantities of inputs or money). In contrast, efficiency is a relationship between an effect (in this case, the production of health) and the monetary means used to achieve it.

There is a traditional consensus that clinical effectiveness constitutes an essential dimension of the concept of quality in that it forms the basis of what Donabedian (1980) has called the "absolutist definition of quality" (p. 13). Under this definition, clinicians are obligated to pursue the greatest improvement in health that science makes possible, regardless of cost. But there is an added, growing consensus that a comprehensive definition of quality must also take into account the costs, both to the individual and to society, of attaining any level of health improvement (Codman 1916; Vuori 1980, 1982; Donabedian 1980, 1988). From this perspective, the highest quality is represented by the strategy of care that can be expected to achieve the greatest improvement in health, while at the same time using the least costly resources. This means that effectiveness and efficiency are to be simultaneously pursued. However, in formulating our model, the intent is to assess the performance of the hospital within the limits of the resource constraints it faces. Under these circumstances, the most efficient performance is also the one that produces the highest feasible level of quality, although that level might fall short of what could 
have been achieved had more resources been available. That is why our model makes no explicit mention of effectiveness; given limited resources, the most efficient performance is also the most effective.

As proposed in Figure 1, clinical efficiency is determined by the appropriateness of the clinical decisions to select a certain strategy of care and by the skill with which the strategy is carried out. In addition, the extent to which a clinician can be held responsible for clinical efficiency depends on the degree and distribution of clinical autonomy in the organization-that is, the authority of clinicians to control the content of their work (Freidson 1970).

Even when a physician has selected the optimal strategy of care, inefficiencies may occur in the process of producing the services that form this strategy, leading to a waste of resources. For example, there may be delays in processing or reporting laboratory tests, the occupancy rate may be low, or the hospital may be using more costly personnel than warranted by the complexity of tasks. Donabedian, Wheeler, and Wyszewianski (1982) suggest that these kinds of inefficiencies in the production of services should not be considered a part of the definition of quality, although they certainly influence the level of quality that is achieved per dollar of expenditure. Hence, production efficiency is dependent, not on clinical judgment, but on the proper specification and implementation of the service production process, so that the amount of services required by a certain strategy of care can be produced at the lowest cost. It should be recognized, however, that the production processes used in an institution are markedly affected by the opinions and preferences of clinicians.

The concepts of clinical efficiency and service-production efficiency introduce a useful distinction into the analysis of the substantive function of a hospital, that is, the production of services that will generate an improvement in health. In a manner parallel to the notion of clinical efficiency, Figure 1 proposes the concept of managerial efficiency. As in the case of clinicians, our model recognizes the importance of managerial effectiveness but places the emphasis of performance assessment on the efficient use of resources. Depending on the level of the manager, the products of managerial efficiency are policies or support services. Like clinical efficiency, managerial efficiency depends on the appropriateness of managerial decisions; the skill in managing the organization (as evidenced, for example, in styles of leadership, capacity to resolve conflict, handling of time, ability with finances, etc.); and managerial autonomy, either from the clinicians or from officials at higher levels of decision making.

The two main actors in our model-clinicians and managers-interact in complex ways. We have already seen that each group can interfere 
with the autonomy of the other. In this respect, there is a general assumption that the autonomy of clinicians is positively associated with clinical efficiency and that the autonomy of managers is similarly associated with managerial efficiency. While this seems to be a reasonable notion on the whole, the relationship may not be linear, so that a system of checks and balances between the clinical and the managerial functions might produce the highest degree of organizational efficiency.

Other points of interaction between managers and clinicians are also schematized in Figure 1. Because of the characteristics of medical work, which is dominated by professionals, both groups participate in the specification and implementation of the production process and therefore determine production efficiency. In addition, the respective products of the two groups of actors are linked, as portrayed in the last column of the diagram. Thus, policies have an influence on support services; policies and support services jointly affect the production of health care services; and health care services, in turn, determine the production of health.

\section{APPROACHES TO ASSESSING PERFORMANCE}

The central concepts in our analytical framework have some important connections with the approaches to assessing hospital performance. We envisage three approaches conforming to the tripartite classification of structure, process, and outcome first proposed by Donabedian (1966). The characteristics of managers and clinicians, of the organizations in which they work, and of the larger environment that contains both individuals and organizations constitute "structure." To the extent that these characteristics, based on current knowledge, can be judged to be good or favorable, we may expect a hospital to perform better than might otherwise be the case. But this is a very indirect, largely conjectural conclusion about performance.

More direct evidence is obtained by the assessment of "process," which is what managers and clinicians actually do. Here, again, our ability to judge the quality of performance depends on what we already know to be effective and efficient ways of performing managerial tasks or caring for patients.

Our category of "products" corresponds, in a formal sense, to Donabedian's category of "outcomes," but it is not entirely the same in substance. Because the original structure-process-outcome model was developed with clinical performance in view, it confined the category of outcomes to changes in health status and to changes in patients' knowledge, attitudes, and behaviors that are likely to influence health status 
directly or through use of health care. Therefore, our categories of "policies," "support services" and, to some extent, "health care services," which stand in the position of "outcomes" to managerial performance, are only structural prerequisites to clinical performance.

The outcome of clinical performance, in our model, is a change in health status. But note that health, through a succession of intermediate products shown in the last column of Figure 1, is the final outcome of managerial performance as well. This means that the performance of an organization, taking into account both managerial and clinical components, can be assessed by the ultimate product or outcome, namely, a change in the health status of individuals and communities.

This particular outcome, besides representing the joint effects of all preceding inputs, has a high degree of socially conferred validity. Therefore, it is not only the criterion by which degrees of goodness in performance are judged; it is also the ultimate measure of success to be used in epidemiological or experimental studies meant to yield new knowledge about the goodness both of different structural characteristics and of alternative ways of managing the hospital and providing patient care. We realize, of course, that health can itself be the means to other valued ends. But it is both convenient and legitimate to consider the production of health to be the primary objective of health care organizations. The uses to which health itself may be put should be left to the analysis of other social institutions.

\section{THE CONTEXT OF PERFORMANCE}

Hospital performance does not occur in a vacuum. As pointed out before, it takes place in the context of an internal organization design, which in turn is surrounded by an external environment. Following the work of Zald (1970), we can classify the variables that operate inside or outside the organization into the economic and the sociopolitical. In order to adapt Zald's original framework to health care organizations, we have expanded it to include an epidemiologic dimension also, as shown in Figure 2. There are many potential variables for each cell in Figure 2. However, we have included only the most pertinent variables for the analysis of the contextual factors that affect hospital efficiency.

We first briefly identify the variables that define the exchanges of a given hospital with its external environment. On the epidemiologic dimension of analysis, performance is greatly influenced by the patterns of health, disease, and injury that characterize the area where the hospital is located. As discussed later on, when these patterns are in rapid transition, they can severely strain hospital resources. With respect to the 
FIGURE 2 Typology of Variables that Affect Hospital Performance

\begin{tabular}{ccc}
\hline $\begin{array}{c}\text { Dimension } \\
\text { of } \\
\text { Analysis }\end{array}$ & External & Type of Relationship \\
\cline { 2 - 3 } Epidemiologic & $\begin{array}{c}\text { Patterns of health, } \\
\text { disease, and injury } \\
\text { in the population }\end{array}$ & $\begin{array}{c}\text { Case mix: physiopathologic, } \\
\text { social, and economic } \\
\text { characteristics of } \\
\text { patients }\end{array}$ \\
Sociopolitical & $\begin{array}{c}\text { Relations with } \\
\text { the state }\end{array}$ & $\begin{array}{c}\text { Power and authority } \\
\text { relations between } \\
\text { managers and } \\
\text { clinicians }\end{array}$ \\
Economic & -Overall economic & Characteristics of \\
conditions & Product and \\
factor markets & process \\
& &
\end{tabular}

sociopolitical dimension, the main set of relationships refers, in most countries, to those that the hospital must establish with the state, either because the hospital is part of a larger network of public organizations, and hence is owned by the state, or because it derives most of its income from social insurance funds or, at the very least, because the hospital is subject to the regulatory authority of the state (Frenk and Donabedian 1987). The hospital also faces a complex external economic environment. At its highest level of aggregation, this environment is formed by the overall economic situation of a country. For example, economic crises impose several constraints that require creative responses on the part of both private and public hospitals. At a more immediate level, the hospital interacts with various product and factor markets. Because this article focuses mainly on issues of staffing, the variable that we consider most important in this respect is the structure and dynamics of the labor market, particularly the professional labor markets from which the hospital must recruit its managers and clinicians.

Moving to the intraorganizational context of the hospital, it is possible to conceptualize case mix as the internal expression of health, disease, and injury patterns in the external environment. We define case mix broadly to include not only the physiopathologic descriptors of patients, but also the social and economic attributes of the cases cared for, a factor 
that helps to characterize the role of the hospital (e.g., whether it serves the poor or an elite). Thus, to the technical requirements that arise from case mix we add the social role and obligations of the hospital. Beyond the relationships with patients, the most important sociopolitical aspects of organization design are those that specify the legitimate power and authority relationships between physicians and managers. Finally, the economic dimension centers on the characteristics of the production process. There are several economic models attempting to interpret the hospital as a firm (Jacobs 1974; Feldstein 1983). For example, Harris (1982) has presented a model based on internal supply and demand functions. Regardless of which model is adopted, some of the basic variables that need to be understood in the internal economic organization of the hospital include the definition of tasks (e.g., the mix of routine and nonroutine tasks), the division of labor, the service production functions, and the systems for assuring the quality of the product.

Figures 1 and 2 should not be seen as rigid depictions of what are actually very complex processes. Nor are they the only possible representation of these processes. ${ }^{1}$ Instead, our conceptual framework is meant simply as a guide to the identification and analysis of more specific research issues.

\section{BASIC ISSUES}

In a first approximation, it is possible to identify three major groups of issues that can orient the formulation of a research agenda on hospital management. One group refers to issues of measurement. Indeed, it is necessary to develop and test specific and sensitive indicators of the various elements that are shown in Figures 1 and 2, especially the three types of efficiency that we have proposed. The second and largest group of issues are substantive. In accordance with our general framework of analysis, these include three subsets: (1) those that refer to the relationships of the hospital with its external context, (2) issues about the internal organization design, and (3) those that have to do with the core of organizational performance. Finally, the third large group of issues is related to the training of hospital managers for efficiency. We next examine each group of issues, so that we can then proceed, in the last section of this article, to outline a research agenda.

\section{MEASUREMENT ISSUES}

Because of the nature of the study, we do not go into great detail in analysis of the issues that deal with operationalization and measurement 
of the concepts proposed in our analytical framework. It should be pointed out, however, that a great amount of methodological work is required in order to answer such basic questions as the following:

-What are sensitive and specific indicators of managerial, clinical, and service-production efficiency?

- How can one assess such attributes as managerial or clinical judgment, skills, and autonomy?

-What is the appropriate measure of hospital output? If services are considered, how should one account for the bundles of activities that go into a hospital day? Should certain by-products of the hospital-such as information, professional education, research, and referral-be included? If output is conceived of as a change in health status, what means are available to solve the problem of attribution, so that a change in health status is validly related to hospital care? Further development of methods dealing with case classification and with standardization of case mix for differences in severity, prognosis, and resource requirements would be high on the research agenda. Perhaps even more pressing, because it has been so neglected, is the development of methods for adjusting the product and for measuring the productivity of hospitals so that variations in the quality of care are adequately represented.

-Given the multidisciplinary nature of hospital care, how can one relate each output to the contribution of distinct inputs? Conversely, how can one assign specific portions of an input (e.g., time equivalents of physicians) to the production of multiple outputs?

These are just a few of the methodological issues that would need to be solved in any specific study of hospital performance.

\section{SUBSTANTIVE ISSUES}

\section{External Environment}

Whole disciplines are devoted to the study of the epidemiologic, economic, and political conditions that prevail in a society. On the other hand, our main interest in this article focuses on the performance core of hospitals, especially as it is affected by training and staffing. Hence, our analysis of the external environment of the hospital will necessarily be limited. Nevertheless, it is fundamental to keep in mind that no 
research agenda on managerial, clinical, or production efficiency can be complete without at least some consideration to the environmental conditions that shape the organization.

A first problem arises in the precise delimitation of what is external and what is internal. Indeed, defining the boundaries of any organization, and especially of a human service organization such as a hospital (Hasenfeld 1983), is not a straightforward matter. For instance, it could be stated that one of the guiding principles of the primary health care approach is the deliberate blurring of the organizational limits of health care facilities so that they reach out into the community with active programs of health promotion, disease prevention, and early detection of cases. As Miles, Snow, and Pfeffer (1982) point out, "the definition of the organization's boundary should be consistent with the problem under investi-' gation" (p. 424). In our case, the purpose is to distinguish operationally between those processes that take place within given hospitals and those that are external to any individual hospital.

Bearing the foregoing caveats in mind, we can proceed to considering some issues that derive from the epidemiologic, sociopolitical, and economic environment of hospitals.

Epidemiologic Environment. The fundamental issue in this respect refers to the capacity of hospitals to adapt to changing patterns of morbidity and mortality in the community. This issue is particularly salient in some developing countries that are experiencing a complex epidemiologic transition (Frenk, Bobadilla, Sepúlveda, et al. 1989). It is beyond the scope of this article to make a detailed analysis of the present characteristics and likely evolution of this transition. Suffice it to point out the following critical problems:

-What information systems can hospitals devise for opportune identification of new trends in basic epidemiologic and demographic variables?

-What economically feasible schemes are available to convert current hospital capacity so that it responds better to the aging of the population, the emergence of chronic ailments, and the new challenges posed by the AIDS epidemic? What new linkages must hospitals develop with other health care facilities so that they can provide the necessary continuity for the long-term management of chronic diseases?

- How must the staffing of hospitals adapt to new epidemiologic and demographic contexts? Is it possible to retrain specialists so that they can take care of different conditions or age groups? What 
is to be done with specialties that become epidemiologically obsolete (witness, for example, the case of phthisiology and tuberculosis hospitals)?

Sociopolitical Environment. Out of the whole gamut of sociopolitical variables that confront a hospital, we will concentrate, as indicated earlier, on those that have to do with its relationship to the state. ${ }^{2}$ In a long process that began approximately during the eighteenth century (Foucault 1977; Rosen 1979), the state has become the largest owner, payer, or regulator in the health industry of practically every country, so much so that Donnangelo (1975) speaks of the "universality" of state intervention in medical care (p. 4). In fact, it would be impossible to understand the dominant role of hospitals without reference to the fact that, especially since the 1950s, a growing number of governments have adopted and stimulated a paradigm of medical care based on specialty care of high technological complexity in hospitals (Frenk 1983). Likewise, the current concern with the high cost and low coverage of hospitals has been largely prompted by governments that have begun to shift toward a new paradigm based on the tenets of primary health care. Even the search for formulas to stimulate private sector participation in the financing and provision of health care have many times been conducted by governments seeking to reduce their financial risk in this area. In fact, those countries that have adopted explicit formulas to reduce state intervention have found that the public sector still remains as the principal actor in the health field (see, for example, Klein 1984).

There are two main spheres in which the relationship with the state has direct consequences for the performance of hospitals. The first one refers to reimbursement formulas, which have been shown to affect the internal power equilibrium between managers and clinicians (Young and Saltman 1983; Spivey 1984). The second deals with the limitations that government imposes on managerial autonomy, especially in public hospitals that form part of larger bureaucracies such as ministries of health. Actually, these limitations also appear to be imposed in private multihospital systems (Weil and Stam 1986). Thus, an important question for research would be to find out whether the critical variable is the type of ownership of the hospital-public versus private-or the existence per se of an additional layer of managers that controls several hospitals. The same can be said about agencies that certify and regulate hospitals, which can be public, quasi-public, or private in different countries. It is necessary to determine whether their organizational characteristics are similar, resulting in all cases from the nature of their regulatory function, or whether, on the contrary, the type of ownership introduces substantial differences in the way the function is organized. 
Apart from these questions of ownership are a number of important issues that derive from the two spheres of state involvement in hospital performance:

-What reimbursement mechanisms are there that will generate incentives for managerial and service-production efficiency without reducing clinical efficiency?

-Should the state attempt to control hospital performance mostly through incentive systems based on reimbursement, or should it attempt more direct supervision and control? What is the role of consumer groups in this process? How can accountability to the public be maintained in government-run hospitals?

-In the case of public hospitals, should goals be set by each hospital, or should goal setting be a function of the larger public organization to which the hospital belongs? Should ministries of health actually run hospitals, or should their role be limited to setting, enforcing, and supervising standards of care? What mechanisms are there to increase managerial autonomy in public hospitals? What are the consequences of decentralizing goal-setting and operating authority to hospitals in a previously centralized system? What formulas are there to monitor performance in a decentralized system?

Economic Environment. Issues dealing with the economic environment of the hospital will be approached on two different levels. The first one refers to the overall economic situation of a country. The second one has to do with the immediate environment represented by the markets in which the hospital must act.

The fundamental issue at the higher level of analysis is the adaptive response of hospitals to situations of economic crises such as those faced by many developing nations. Economic crises seem to have a dual effect on hospitals. On the one hand, health conditions tend to deteriorate (Brenner 1979; Brenner and Mooney 1983), so that the need for hospital services increases. At the same time, however, the standard policy response to such crises has been to cut budgets for social programs, including health care (Soberón, Frenk, and Sepúlveda 1986). Public hospitals face an additional burden, since they have to absorb part of the demand previously satisfied by private facilities that a growing number of clients can no longer afford. As hospitals in many countries attempt to deal with this complex set of strains, several important questions for research emerge:

-What are the cost savings and effectiveness of alternative modes for providing services that have traditionally been the domain of 
general hospitals, such as normal deliveries or minor surgery? Is it economically and clinically feasible in developing countries to shift to alternative settings for care that may satisfy a larger volume of demand at lower costs and with acceptable quality (e.g., "birth centers" or ambulatory surgery centers)?

- How effective might new methods of financing, such as community prepayment schemes, be in dealing with some of the consequences of economic crises on the utilization and financing of hospitals?

-What mechanisms can be designed to improve the flow and control of material resources within hospitals so that waste can be prevented?

-More generally, what survival strategies must hospitals employ under conditions of economic strain?

Intimately linked to this last question is the issue of the ways in which hospitals participate in the product and factor markets that form their immediate economic environment. As we pointed out earlier, our current focus on issues of staffing makes it necessary to restrict the discussion specifically to labor markets.

The entire world has witnessed a dramatic increase in the supply of physicians. As Kindig and Taylor (1985) demonstrate, this increase has occurred in countries at all levels of economic development. Thus, from 1950 to 1979 the number of physicians per 10,000 people grew by 96 percent in industrialized countries, by 223 percent in centrally planned economies, by 164 percent in middle-income nations, and even by 29 percent in low-income countries. The growing supply of physicians changes the operating environment of the hospital in two fundamental ways. In the first place, it gives the hospital, as an employer, greater leverage to impose working conditions that are more favorable to its interests. In the second place, as the competition for profitable clinical positions increases, it is likely that more doctors will shift from patient care to management (Tarlov 1983). Indeed, it has been shown that physicians' career preferences are significantly affected by their perceptions of the medical labor market (Frenk 1985). As the conditions in this market become more difficult for doctors, they will increasingly seek stable employment through salaried positions, with less clinical autonomy and larger managerial responsibility, and with greater stratification within the medical profession (Freidson 1985). Further, to the extent that in many underdeveloped countries the increasing supply of physicians has not been accompanied by a similar growth of paramedical and technical occupations, it is not unrealistic to expect that some doctors will fill less 
skilled positions in the hospital, giving way to a new kind of medical underemployment. To the suboptimal utilization of personnel within their borders, many countries add the burden of outmigration of their most skilled professionals (Jain 1988). In sum, the main issues that derive from the foregoing considerations can be synthesized as follows:

-What are the implications of an increasing supply of physicians for the hiring and staffing practices of hospitals? Should the substitution of physicians for less skilled positions be allowed and even encouraged? Should hospitals expand their staffs of residents to accommodate the growing demand for graduate medical education, or should they strictly maintain the number that they require to fulfill their medical care functions?

-What negotiating mechanisms can be established between the institutions that hire health care personnel-hospitals among them-and those that produce them-that is, professional schools? What is the relative effectiveness of alternative means for joint human resource planning in the health care field? Should hospitals participate in decisions regarding the quantity and quality of graduates from professional schools? Conversely, should these schools have a say in defining staffing patterns at various types of hospitals?

-In order to contain competition, practicing physicians are likely to impose barriers to the attainment of hospital privileges by their younger colleagues. Should management intervene to reduce such barriers? Should it press for an increase in salaried positions at the hospital?

-Faced with a choice between physicians and administrators as the senior managers of the hospital, what criteria should guide the higher authorities in their hiring policy? Should physicians be preferred, as they are in many countries, simply because they are knowledgeable about the substantive functions of the hospital? Or should managerial efficiency be the guiding criterion?

As can be seen, some of these issues begin to have a direct bearing on the design of the hospital, a topic to which we turn next.

\section{Organization Design}

Organization design has been defined as "the way authority, responsibility and information are combined within a particular organization" (Leatt, Shortell, and Kimberly 1987, 307). A design "tailor[s] the organization so that it can monitor its environment and respond to the 
constraints and opportunities presented by the environment" (p. 307) as it achieves coordination and integration of tasks across parts of the organization (Lawrence and Lorsch 1967).

As mentioned earlier, defining the precise boundaries of organizations is not a straightforward matter. In particular, hospitals face a number of very important issues related to the overall design of the health system, especially their relationships with other hospitals and health care facilities, including the problems of regional organization, multihospital systems, vertical and horizontal integration, and cooperation and competition among hospitals (Longest 1981). Taking into account the context of interorganizational design, this section of the article concentrates on questions of intraorganizational design.

Two main issues define different types of designs: the grouping and prioritizing of activities within the organization and the means by which decisions are made. In fact, these issues illustrate two different analytical dimensions of the same concept. On the one hand, the organization design is represented by the structure, that is, the type, number, and size of units, spans of control, and arrangement of units along the lines of authority. On the other, one can identify the more subtle and dynamic elements of an organization's design, such as degree of centralizationdecentralization, standardization, formalization, and mechanisms for coordination, communication, and control, as well as reward systems. Both dimensions, in turn, are determined by the internal epidemiologic, sociopolitical, and economic relationships that are shown in Figure 2.

This section focuses mainly on the structural issues: Since there is more evident relationship between the more dynamic elements of organization design and organizational performance, these are analyzed in the next section.

Three types of structures have been traditionally identified: functional, divisional, and matrix (Daft 1983). Functional structure means a division of labor into departments specialized by functional area, that is, departments of surgery, medicine, nursing, medical records, and so on. Leatt, Shortell, and Kimberly (1987) mention that this type of structure is more common in relatively small (100-200 bed) community general hospitals. On the other hand, divisional structures are organized around services having, in many cases, their own clinical and administrative support services. This type of structure may be seen more often in large teaching hospitals (Howe 1969). Finally, matrix structures are the most infrequent ones in hospitals. They are characterized by a dual authority system designed to improve lateral coordination and information flow across the organization (Neuhauser 1972; Gray 1974).

All of these possible configurations might respond to traditional arrangements of the structure rather than to actual environmental demands 
or to the need to improve organizational performance (Mintzberg 1981). If one considers the possible role of hospitals in primary care provided through outreach programs, one could ask which of these structural alternatives is the most appropriate (Shortell, Wickizer, and Wheeler 1984; Aday, Andersen, Loevy, et al. 1984; Mintzberg 1979).

In addition, it is very important to consider the particular characteristics of hospital structures where two chains of command coexist. For Mintzberg (1981), hospitals are a "professional bureaucracy," since their structural configuration relies on trained professionals who must be given considerable control over their own work. In this case, one can identify parallel hierarchies, one for the professionals and another for the support staff.

The existence of two main chains of command in hospitals-medical staff and administration-has been well documented by several authors in developed countries (Perrow 1961; Georgopoulos 1962; Bucher and Stelling 1969; Engel 1969; Scott 1973; Robb 1975; Longest 1980; Shortell and Evashwick 1981; Scott 1982; Leatt, Mickevicius, Barnsley et al. 1983; Kinston 1983). However, in developing countries the high predominance of clinicians over professional managers in hospital administration might blur the limits between the two hierarchies. This is even more likely when one considers that in most government-owned hospitals physicians are salaried; therefore, they are accountable not to the medical staff organization but to the administration.

The notion of the dual-authority structure leaves the role of nursing in an ambiguous position. In many countries, nurses face the problem of "multiple subordination": the nurse is responsible to the attending physician and also to the nursing supervisor and, through the nursing supervisor, to the hospital administrator. In addition to clinical functions, nurses often seem to be given physician-behavior control functions. In terms of our analytical framework (Figure 1), nurses may often be placed in a conflicting position between maximizing managerial or clinical efficiency.

From these aspects of the structural dimension of organization design in hospitals, several issues can be identified:

-When physicians predominate in top administrative positions, can two chains of command still be clearly identified? Is the scope of their expert power clinical, managerial, or both? How does this situation influence the professional autonomy of clinicians and professional managers?

-What structural arrangements are necessary to improve the balance between these two groups so that technical expertise in medicine and administration can be better allocated? What is the 
role of nurses in the various schemes for the distribution of authority among physicians and managers?

-Within a particular type of structure, how and by whom are the goals of the hospital defined?

-Communication among members of different professional groups in hospitals has always been a difficult task, not only because of their different backgrounds but also because of deficiencies in organization design (Robb 1975). This is also true with regard to communication between providers and clients. How can hospital organization be better designed to improve the flow of information among departments, providers, and clients (Hasenfeld 1983)?

-What are the different implications of the organization design of private versus public hospitals for clinical, managerial, and production efficiency?

-What are the advantages and disadvantages of functional, divisional, or matrix structures for hospitals in countries with various kinds of health care systems?

-What might be the best alternatives for structuring the organization of hospitals according to their external context, size, and types of services provided?

-In light of the goal of "Health for All by the Year 2000," what are the best alternatives for designing the hospital organization in order to provide the highest level of access to hospital resources?

-Which environmental variables have major effects on hospital design? What is their impact? How are these variables operating to influence hospital design in different countries?

\section{Organizational Performance}

Improving organizational performance is perhaps the most important challenge to any hospital administrator. Shulz and Johnson (1976) have proposed some selected managerial practices for improving performance. These practices can be grouped into three main areas: management of quality, management of costs, and management of conflict.

Management of quality involves, among other things, the implementation of assessment and monitoring systems and of quality assurance mechanisms based on a sound organization design. The latter includes managerial decisions regarding the degree of standardization and formalization of clinical and nonclinical tasks, the degree of decentralization, and the implementation of adequate coordination and communication mechanisms through the development of quality assurance programs. 
Further, managerial decisions have to be made regarding the types of incentives and specific control mechanisms for clinical performance. Another very important aspect of the management of quality has to do with staffing. Several authors have studied the relationships between hospital medical staff organization and the quality of care (Shortell and LoGerfo 1981; Flood and Scott 1978; Roemer and Friedman 1971). A critical question in this respect refers to the effects of alternative forms of physician recruitment, affiliation, determination of privileges, incentive reimbursement, and promotion on clinical efficiency.

Staffing is also a relevant aspect of the management of costs. Pauly (1978), Garg, Mulligan, Gliebe, et al. (1979), and Sloan and Becker (1981) have analyzed different aspects of the relationship between medical staff and costs. The ratio of management to production personnel as it affects the efficiency of hospitals has been studied by Rushing (1974). In addition, it is necessary to examine the problem of function allocation among staff members according to their qualifications; this problem is related to the question of flexibility in staffing to adjust both to fluctuations in demand and to long-term changes in case mix, such as those that the epidemiologic transition can bring about.

Scott and Shortell (1983) have made an extensive review of the literature both on effectiveness and on efficiency, as they relate to the management of quality and the management of costs. It is very important to mention that both managerial practices require a well-designed information system that allows managers to obtain a true image of hospital performance so that decisions are made on a solid basis.

Management of conflict is of paramount importance in hospitals given the different professional groups involved in patient care. Organization design, along with goal-setting and negotiating skills, are the best elements for managing conflict. Again, a clear organization design tends to improve communication and coordination, and to prevent conflict by defining authority and responsibility among hospital staff.

In sum, organizational performance seems to be associated with an active linkage to the organizational environment, an appropriate organization design, and the existence of information systems that provide both awareness of organizational functioning and the opportunity to take corrective action (Scott and Shortell 1983).

Many issues could be raised around organizational performance. Some of them have already been mentioned in other sections of this article, particularly with regard to the relationships between the organization and its external environment and among some aspects of organizational design. Nevertheless, other relevant issues remain that deserve consideration: 
-Which are the most common mechanisms in different types of countries to link hospitals with their external environment?

-What is the role of community members in the administration of hospitals?

-What should be the composition of hospital boards?

- Since quality-assurance experiences are only beginning in many countries, what might be the strategies for implementing such programs? What characteristics of an information system might be needed in order to run an efficient and effective qualityassurance program?

- Three types of quality-assurance systems can be identified by the degree of decentralization and hospital staff involvement: centralized, decentralized nonparticipative, and decentralized participative (Ruelas and Frenk 1987). What should be the degree of decentralization for quality-assurance activities? What are the best mechanisms for involving hospital staff in quality-assurance programs?

- How much standardization and formalization of professional activities is necessary to assure quality of care?

-What might be the incentive for clinicians to increase their compliance with standards of care?

-Who should supervise the different professional activities within the hospital?

- What should be the adequate ratios of general practitioners to specialists, doctors to nurses, clinical personnel to support personnel, according to case mix, in order to maintain an efficient level of hospital performance?

-What should be the criteria for establishing a medical staff to residents ratio that assures adequate-supervision and quality of care?

- How can the participation of clinicians in hospitalwide decision making be improved?

-What kind of coordination and communication mechanisms might be implemented among hospital departments to prevent conflicts and improve continuity of care?

\section{ISSUES RELATED TO THE TRAINING}

\section{OF HOSPITAL MANAGERS}

In accordance with the framework proposed in this article, managerial efficiency is a result of three main components: decision making, 
skills, and autonomy. We have already mentioned several aspects of managerial decision making directed at improving hospital performance, as well as some issues regarding the relative professional autonomy of managers within the hospital structure.

According to Katz (1974), three kinds of skills-conceptual, technical, and human-are necessary for the adequate performance of an effective administrator role. On the other hand, the object of several studies is an attempt to elucidate the different types of roles that administrators perform (Mintzberg 1975; Kuhl 1977; Allison, Dowlig, and Munson 1983).

The development of managerial skills to perform different roles adequately depends on two important aspects: experience and training. Given the complexity of hospital administration, learning through dayto-day experience might be a trial-and-error process that is very costly for the organization. Even though formal training cannot substitute for field experience, it does provide a broader frame of reference for decision making and facilitates the process of learning from field experiences.

Ruelas and Leatt (1985) have proposed that three aspects be considered in designing training programs: the level of the executive within the structure, the types of administrative problems perceived at a specific level, and the kinds of roles to be performed to deal with these problems. At the same time, the development of conceptual, technical, and human skills should be considered, again according to the hierarchical level of the hospital executive. Specific programs and contents can then be established.

It is interesting to recall that hospital administration is a relatively new discipline. Hospitals in North America have been dominated by different groups in a rather regular succession (Perrow 1961). In an earlier time, when community support was needed to build and finance hospitals, trustees dominated and the basis for their control was primarily financial. Then, with advances in science and technology, major decisions had to be based on a medical competence that trustees did not possess, so physicians became the dominant group. As hospitals became more complex organizations and needed more coordination, hospital administrators acquired increased power.

This evolution might not be the same in developing countries, where physicians still tend to dominate and where hospital administration is not yet well established. The implications of this situation are twofold: first, there is a need to provide clinicians with a better understanding of hospital administration so that they can improve their managerial performance; second, it is necessary to professionalize health care management by establishing formal training programs in this field, which by necessity will include physicians as well as other occupational groups. 
Different options for providing adequate training in hospital administration-namely, master's, doctoral, continuing education, and even undergraduate programs-have to be better explored in developing countries. Sending students to developed countries for their training represents a different kind of alternative that must also be considered.

The following issues illustrate just some of the major questions that need to be answered:

- How are managerial problems perceived by hospital executives at different levels of the hierarchy and in different types of hospitals? How can training programs be designed to take account of such variation? What should be the main contents of these programs?

- As training programs for health services administrators have faced growing competition from programs in business administration, one response has been to emphasize the strictly managerial aspects in the curriculum, at the expense of health contents such as epidemiology. If, however, hospitals must respond to their changing epidemiologic environment, this trend could have very negative consequences. What new training approaches can be devised offering future health care managers the complex contents of managerial science while at the same time preserving the fundamental concepts and methods of epidemiology? If such an integrative approach is not feasible, will it become necessary to place an epidemiologist in the senior management group of a hospital?

- How should existing training programs in health care administration respond to the increase in the number of physician administrators? Should new programs, different from the traditional master's degrees, be designed to meet the special backgrounds and needs of physicians?

-Regarding the level of training, would undergraduate programs in hospital administration be useful? Should professionally oriented or academically oriented postgraduate programs predominate? Should a sharp distinction be developed between the types? What should be the role of master's, doctoral, and continuing education programs in meeting the needs of student hospital administrators in developing countries?

- How convenient is residency training in health care administration, under what circumstances, and for how long?

-Do enough faculty exist in developing countries to support highquality education in hospital administration? What might be the strategies for faculty development?

- How useful is the training of professionals in foreign countries, as opposed to concentrating on their own cultural experiences? 
What strategies should be considered to assure that experiences obtained abroad will have an effect in the trainees' countries when they return? How useful are exchange programs between developed and developing nations? What should be done to take advantage of such programs in order to achieve a balance between academic quality, on the one hand, and relevance to the context of the trainee, on the other?

-What role should ethics assume in the training of hospital administrators? In what way can training programs help to shape the social function of the hospital? How can the demands of social responsibility and economic solvency be balanced? In situations of conflict among the interests of the patient, the institution, the clinician, or the insurer, what are the guidelines for ethical behavior, if any? Is the hospital responsible for the care only of those who enter it and only during the time they are there? Does a responsibility exist for discharged patients? Is there responsibility for access? What is the role of training programs in generating the type of social consensus that may allow a constructive approach to these critical questions?

\section{TOWARD A RESEARCH AGENDA}

Most of the issues that we have discussed throughout this article represent important topics for research. The fact that we posed them as questions was intended, precisely, to emphasize how researchable these issues are and to convey the sense that it is necessary to seek answers through sound studies. The problem, of course, is that the number of issues is too large to constitute a workable research agenda; it is necessary to establish priorities. In this last section of the article we briefly sketch possible priorities.

A first consideration in designing a research agenda on a topic such as hospital management is to strive for a balance between relevance to decision making and excellence in the strict adherence to the norms of scientific research (Frenk, Bobadilla, Sepúlveda, et al. 1986). Within this broad guideline, priorities must be defined on two dimensions: the type of research and the topics to be researched.

With respect to the former, we believe that the order of priorities should begin with observational studies that document levels of hospital performance and correlate them with organization design and environmental variables. Apart from offering basic descriptions that are much needed, especially in developing countries, this type of study would make it possible to operationalize and measure the constructs that we have 
proposed in our analytical framework. As indicated in the section on measurement issues, it is particularly important to devise and test sensitive and specific indicators of managerial, clinical, and service-production efficiency. In addition, it is necessary to determine the internal and external correlates of these dimensions of performance.

Observational studies would make it possible to diagnose the most critical areas for the second type of research-intervention studies that would introduce planned change in hospitals and would assess its consequences. It is fundamental that intervention studies be based on comparative designs. Indeed, a problem with evaluations of the effectiveness of specific interventions is the frequent lack of control groups, a problem that makes it impossible to attribute any observed change to the intervention itself rather than to another source of variation. The external validity of this type of study is also often threatened by the choice of highly specific sites that make it very difficult to generalize the findings and to build a true body of knowledge. If the ideal of randomized trials cannot be achieved, then quasi-experimental designs with clear control groups should be used. These kinds of studies should be complemented by costbenefit and cost-effectiveness analyses of the interventions (Wortman 1983).

Turning to priorities on the topics for research, it must be stated at the outset that any ranking of topics is doomed to seem arbitrary unless it is based on some explicit method to poll the perceptions of large numbers of experts and consumers of research. Nevertheless, we will attempt to offer what we believe is a preliminary list of the most urgent areas for inquiry.

The first need is for good descriptive studies of the hospital system and of the main aspects of organization design. Studies of this type should be based on widely accepted classifications and nomenclatures that can be used in comparative studies across nations. To date, many countries lack even basic information on the composition and characteristics of hospitals. Critical items that are often not known include the exact magnitude of the private sector, the proportion of total health care resources that is absorbed by hospitals, and the unit costs for specific hospital servicesand these are only a few. Furthermore, there is a paucity of data on the structure of hospital organization. Whereas in developed countries extensive empirical studies have been conducted to define, for example, the two lines of authority, in many developing nations we are often ignorant of the ways in which formal and informal relations between and among managers and clinicians are structured. Likewise, it is necessary to know the frequency of different arrangements for internal communication, types of departmentalization, and management systems.

The second priority goes beyond broad comparisons of hospital structures across nations in referring to the systematic study of quality 
monitoring and assurance systems. In the final analysis, hospitals should be producing improvements in health, however we define the concept. The design and testing of explicit systems to assure the quality of care would therefore seem to be of the highest importance if we are to gain some understanding of what exactly hospitals are contributing to society and at what cost. Such studies should include analyses of the interactions between managers and clinicians, especially as they constrain clinical autonomy and decision making. As pointed out earlier in this article, several variants of quality-assurance systems exist for hospitals. Assessment of their relative effectiveness and costs should be a high-priority item on a research agenda.

The third area for research centers on the social, personal, organizational, and educational determinants of managerial skill. Indeed, we need to know what the factors are that account for different degrees of success in managing a hospital. These studies should not be limited to psychological variables, although they should certainly include them. The main challenge is to ascertain the relative contributions to managerial skill of personal variables versus educational background and organizational structure. Clearly, this kind of study would have major policy implications for the recruitment and training of hospital managers which, in turn, might help to alleviate the shortage of skilled management, especially in underdeveloped countries.

Finally, the magnitude, repercussions, visibility, and universality of physician oversupply make this a high priority for research. In this respect, we are in need of studies about the structure and dynamics of medical labor markets, which would allow us to understand the origins of the oversupply of doctors and the reasons for its occurrence in such a wide variety of countries. The coexistence, in many nations, of medical underemployment with a lack of universal access to medical care is probably the most eloquent indicator of the shortcomings of current ways of organizing health systems. Hospitals are undoubtedly a major part of this problem. We should therefore understand the consequences of the oversupply of physicians on the operation and staffing of hospitals, and its significance for the design of innovative training programs.

While still incomplete, this initial research agenda might begin to illuminate some of the basic issues that concern policymakers, managers, clinicians, and clients in the common search for higher levels of performance in health care.

\section{ACKNOWLEDGMENTS}

We would like to acknowledge the help of Beatriz Zurita, Michal Frejka, Luis Miguel Vidal, and Marlene Llopiz in completing the literature search and 
organizing the material. The first version of this article was prepared at the request of Howard Barnum, Ph.D., from the Policy and Research Division of the Population, Health and Nutrition Department at the World Bank. The views expressed in this article, as well as its shortcomings, are solely the responsibility of the authors.

\section{NOTES}

1. For a different (though related) approach, see Kovner and Neuhauser (1983).

2. As has become increasingly customary in the literature, we adopt the narrow definition of the state as the institutions of government providing the administrative, legislative, and judicial vehicles for the actual exercise of public authority and power, instead of the broad definition of the state as the total political organization of a society, including its citizens.

\section{REFERENCES}

Aday, L. A., R. Andersen, S. S. Loevy, and B. Kremer. "Hospital-Sponsored Primary Care: II. Impact on Patient Care." American Journal of Public Health 74, no. 8 (1984): 792-98.

Allison, R. F., W. L. Dowlig, and F. C. Munson. "The Role of the Health Services Administrator and Implications for Educators." In Health Services Management: Readings and Commentary, $2 \mathrm{~d}$ ed. Edited by A. R. Kovner and D. Neuhauser. Ann Arbor, MI: Health Administration Press, 1983, 32-67.

Berki, S. E. Hospital Economics. Lexington, MA: Lexington Books, 1972.

Brenner, M. H. "Mortality and the National Economy: A Review and the Experience of England and Wales, 1936-76." Lancet 2, no. 8142 (1979): 568-73.

Brenner, M. H., and A. Mooney. "Unemployment and Health in the Context of Economic Change." Social Science and Medicine 17, no. 16 (1983): 1125-38.

Bucher, R., and J. Stelling. "Characteristics of Professional Organizations." Journal of Health and Social Behavior 10, no. 1 (1969): 3-15.

Codman, E. A. A Study in Hospital Efficiency. Boston: Thomas Todd Co., Printers, 1916.

Daft, R. L. Organization Theory and Design. St. Paul: West Publishing Co., 1983.

Donabedian, A. "Evaluating the Quality of Medical Care." Milbank Memorial Fund Quarterly 44, no. 3 (1966): 166-203.

Explorations in Quality Assessment and Monitoring, Vol. 1: The Definition of Quality and Approaches to its Assessment. Ann Arbor, MI: Health Administration Press, 1980.

"Quality and Cost: Choices and Responsibilities." Inquiry 25, no. 1 (1988): 90-99.

Donabedian, A., J. Wheeler, and L. Wyszewianski. "Quality, Cost, and Health: An Integrative Model." Medical Care 20, no. 10 (1982): 975-92.

Donnangelo, M. C. F. Medicina e Sociedade: O Médico e seu Mercado de Trabalho. Sao Paulo: Livraria Pionera Editora, 1975. 
Engel, G. V. "The Effect of Bureaucracy on the Professional Autonomy of the Physician." Journal of Health and Social Behavior 10, no. 1 (1969): 30-41.

Feldstein, P. J. Health Care Economics, $2 \mathrm{~d}$ ed. New York: John Wiley \& Sons, 1983.

Flood, A. B., and W. R. Scott. "Professional Power and Professional Effectiveness: The Power of the Surgical Staff and the Quality of Surgical Care in Hospitals." Journal of Health and Social Behavior 19, no. 3 (1978): 240-54.

Foucault, M. "Historia de la Medicalización." Educación Médica y Salud 11, no. 1 (1977): 3-25.

. "Incoporación del Hospital en la Tecnología Moderna." Educación Médica y Salud 12, no. 1 (1978): 20-35.

Frederiksen, H. "Feedbacks in Economic and Demographic Transition." Science 166, no. 3907 (1969): 837- 47.

Freidson, E. Profession of Medicine: A Study in the Sociology of Applied Knowledge. New York: Harper and Row, 1970.

"The Reorganization of the Medical Profession." Medical Care Review 42, no. 1 (Spring 1985): 11-36.

Frenk, J. "Career Preferences under Conditions of Medical Unemployment: The Case of Interns in Mexico." Medical Care 23, no. 4 (1985): 320-32.

. Social Origin, Professional Socialization, and Labor Market Dynamics: The Determinants of Career Preferences among Medical Interns in Mexico. Ph.D. diss., The University of Michigan, Ann Arbor, MI, 1983.

Frenk, J., and A. Donabedian. "State Intervention in Medical Care: Types, Trends and Variables." Health Policy and Planning 2, no. 1 (1987): 17-31.

Frenk, J., J. L. Bobadilla, J. Sepúlveda, and M. López-Cervantes. "Health Transition in Middle-Income Countries: New Challenges for Health Care." Health Policy and Planning 4, no. 1 (1989): 29-39.

Frenk, J., J. L. Bobadilla, J. Sepúlveda, et al. "An Innovative Approach to Public Health Research: The Case of a New Center in Mexico." Joumal of Health Administration Education 4, no. 3 (Summer 1986): 467-81.

Garg, M. L., J. L. Mulligan, W. A. Gliebe, et al. "Physician Specialty, Quality and Cost of Inpatient Care." Social Science and Medicine 13c, no. 3 (1979): 187-90.

Georgopoulos, B. S., and F. C. Mann. The Community General Hospital. Toronto: Macmillan, 1962.

Gray, J. L. "Matrix Organizational Design as a Vehicle for Effective Delivery of Public Health Care and Social Services." Management International Review 14 (1974): 73-82.

Harris, J. E. "The Internal Organization of Hospitals: Some Economic Implications." In Issues in Health Economics. Edited by R. Luke and J. C. Bauer. Rockville, MD: Aspen Systems Corp., 1982, 183-97.

Hasenfeld, Y. Human Service Organizations. Englewood Cliffs, NJ: Prentice-Hall, 1983.

Howe, G. E. "Decentralization Aids Coordination of Patient Care Services." Hospitals 43, no. 1 (1969): 53-55.

Jacobs, P. "A Survey of Economic Models of Hospitals." Inquiry 11, no. 2 (1974): $83-97$. 
Jain, S. C. "A Diagnostic Approach for the Improvement of Health Manpower Management." Health Services Management Research 1, no. 2 (1988): 101-11.

Katz, D. "Skills of an Effective Administrator." Harvard Business Review 52, no. 1 (1974): 90-120.

Kindig, D. A., and C. M. Taylor. "Growth in the International Physician Supply. 1950 through 1979." Journal of the American Medical Association 253, no. 21 (1985): 3129-32.

Kinston, W. "Hospital Organization and Structure and its Effect on Inter-Professional Behavior and the Delivery of Care." Social Science and Medicine 17, no. 16 (1983): 1159-70.

Klein, R. "The Politics of Ideology vs. the Reality of Politics: The Case of Britain's National Health Service in the 1980s." Milbank Memorial Fund Quarterly/Health and Society 62, no. 1 (1984): 82-109.

Kovner, A. R., and D. Neuhauser. "Introduction." In Health Services Management: Readings and Commentary, $2 \mathrm{~d}$ ed. Edited by A. R. Kovner and D. Neuhauser. Ann Arbor, MI: Health Administration Press, 1983, 3-18.

Kuhl, I. K. The Executive Role in Health Service Delivery Organizations. Washington, DC: Association of University Programs in Health Administration, 1977.

Lawrence, P., and J. Lorsch. Organization and Environment. Managing Differentiation and Integration. Boston: Harvard Business School Press, 1967.

Leatt, P., S. Shortell, and J. R. Kimberly. "Organization Design." In Health Care Management: A Text in Organizational Theory and Behavior, 2d ed. Edited by S. Shortell and A. Kaluzny. New York: John Wiley \& Sons, 1987, 307-43.

Leatt, P., V. Mickevicius, J. Barnsley, et al. Hospital Medical Staff Organization: An Armotated Bibliography. Ottawa: Canadian Hospital Association, 1983.

Longest, B. B. "A Conceptual Framework for Understanding the Multihospital Management Strategy." Health Care Management Review 5, no. 1 (Winter 1980): 17-24.

"An External Dependence Perspective of Organizational Strategy and Structure: The Community Hospital Case." Hospital and Health Services Administration 26, no. 2 (Spring 1981): 50-69.

Mechanic, D. "Ideology, Medical Technology, and Health Care Organization in Modern Nations." American Joumal of Public Health 65, no. 3 (1975): 241-47.

Miles, R. E., C. C. Snow, and J. Pfeffer. "Organization-Environment: Concepts and Issues." In Issues in Health Care Management. Edited by S. Spirn and D. W. Benfer. Rockville, MD: Aspen, 1982, 421-38.

Mintzberg, H. "Organizational Design: Fashion or Fit." Harvard Business Review 59, no. 1 (January-February 1981): 108-116.

. "The Manager's Job: Folklore and Fact." Harvard Business Review 53, no. 1 (1975): 49-61. Inc, 1979.

. The Structuring of Organizations. Englewood Cliffs, NJ: Prentice-Hall,

Neuhauser, D. "The Hospital as a Matrix Organization." Hospital Administration 17, no. 1 (1972): 8-25.

Omran, A. R. "The Epidemiologic Transition: A Theory of the Epidemiology of Population Change." Milbank Memorial Fund Quarterly 49, no. 4 (1971): 509-38. 
Pauly, M. "Medical Staff Characteristics and Hospital Costs." Journal of Human Resources 13, no. 1 (1978): 78-111.

Perrow, C. "The Analysis of Goals in Complex Organizations." American Sociological Review 26, no. 6 (1961): 836-66.

Robb, J. H. "Power, Profession and Administration: An Aspect of Change in English Hospitals." Social Science and Medicine 9, no. 9 (1975): 373-82.

Roemer, M., and J. Friedman. Doctors in Hospitals: Medical Staff Organization and Hospital Performance. Baltimore, MD: Johns Hopkins University Press, 1971.

Rosen, G. "The Evolution of Social Medicine." In Handbook of Medical Sociology, 3d ed. Edited by H. E. Freeman, S. Levine, and L. G. Reeder. Englewood Cliffs, NJ: Prentice-Hall, 1979, 23-50.

. "The Hospital: Historical Sociology of a Community Institution." In The Hospital in Modern Society. Edited by E. Freidson. London: The Free Press of Glencoe, 1963, 1-36.

Ruelas, E., and P. Leatt. "The Roles of Physician-Executives in Hospitals: A Framework for Management Education." Joumal of Health Administration Education 3, no. 2, Part I (1985): 152-69.

Ruelas, E., and J. Frenk. "Quality Circles: An Innovative Experience of Quality Assurance in Mexico." Presented at the Fourth International Invitational Symposium on Quality Assurance, Copenhaguen, 26-29 May 1987.

Rushing, W. "Differences in Profit and Non-Profit Organizations: A Study of Effectiveness and Efficiency in General Short Stay Hospitals." Administrative Science Quarterly 19, no. 4 (1974): 473-84.

Scott, W. R. "Managing Professional Work: Three Models of Control for Health Organizations." Health Services Research 17, no. 3 (Fall 1982): 213-40. . "Some Implications of Organization Theory for Research on Health Services." Milbank Memorial Fund Quarterly 44, no. 4 (1966): 35-64.

"The Medical Staff and the Hospital: An Organizational Perspective." The Hospital Medical Staff 2, no. 1 (1973): 33-38.

Scott, W. R., and S. Shortell. "Organizational Performance: Managing for Efficiency and Effectiveness." In Health Care Management: $A$ Text in Organizational Theory and Behavior. Edited by S. Shortell and A. Kaluzny. New York: John Wiley \& Sons, 1983, 418-55.

Secretaria de Salud. Anuario Estadistico 1984. Mexico, D.F.: Dirección General de Información y Evaluación, 1985.

Shortell, S., and C. Evashwick. "The Structual Configuration of U.S. Hospital Medical Staffs." Medical Care 19, no. 4 (1981): 419-30.

Shortell, S., and J. P. LoGerfo. “Hospital Medical Staff Organization and Quality of Care: Results for Myocardial Infarction and Appendectomy." Medical Care 19, no. 10 (1981): 1041-53.

Shortell, S., T. M. Wickizer, and J. Wheeler. "Hospital-Sponsored Primary Care: I. Organizational and Financial Effects." American Journal of Public Health 74, no. 8 (1984): 784-91.

Shulz, R., and A. C. Johnson. The Management of Hospitals. New York: McGrawHill, 1976. 
Sloan, F., and E. Becker. "Internal Organization of Hospitals and Hospital Cost." Inquiry 18, no. 3 (1981): 224-40.

Soberón, G., J. Frenk, and J. Sepúlveda. "The Health Care Reform in Mexico: Before and After the 1985 Earthquakes." American Journal of Public Health 76, no. 7 (1986): $673-80$.

Spivey, B. E. "The Relation between Hospital Management and Medical Staff under a Prospective-Payment System." New England Journal of Medicine 310, no. 15 (1984): $984-86$.

Starr, P. The Social Transformation of American Medicine. New York: Basic Books, 1982.

Tarlov, A. R. "Shattuck Lecture-The Increasing Supply of Physicians, the Changing Structure of the Health-Services System, and the Future Practice of Medicine." Nezw England Journal of Medicine 308, no. 20 (1983): 1235-44.

Vuori, H. "Optimal and Logical Quality: Two Neglected Aspects of the Quality of Health Services." Medical Care 13, no. 10 (1980): 975-85.

Quality Assurance of Health Services: Concepts and Methodology. Copenhagen: WHO Regional Office for Europe, 1982.

Weil, P. A., and L. Stam. "Transitions in the Hierarchy of Authority in Hospitals: Implications for the Role of the Chief Executive Officer." Journal of Health and Social Behavior 27, no. 2 (1986): 179-92.

Wortman, P. M. "Evaluation Research: A Methodological Perspective." Anmual Review of Psychology 34 (1983): 223-60.

Young, D. W., and R. B. Saltman. "Prospective Reimbursement and the Hospital Power Equilibrium: A Matrix-Based Management Control System." Inquiry 20, no. 1 (1983): 20-33.

Zald, M. N., ed. Power in Organizations. Nashville, TN: Vanderbilt University Press, 1970, 221-69. 